\title{
Framing Digital Tools and Techniques in Built Heritage 3D Modelling: The Problem of Level of Detail in a Simplified Environment
}

\author{
Moulay Larbi Chalal, The University of Salford, UK \\ Riccardo Balbo, Politecnico di Torino, Italy
}

\begin{abstract}
Recently, the built heritage sector has witnessed an increase demand for $3 D$ models of historical sites mainly due to the widespread of new technologies in buildings' surveying. Although these technologies have been credited for enabling highly detailed $3 D$ modelling of the built heritage, their implementation is still so complex and costly. This research aims to explore the possibility of implementing new low-cost digital acquisition technologies and modelling techniques as an alternative to the existing expensive ones in terms of level of detail (LOD), as an attempt to enable lowskilled users in simplified environment, which are faced paced leaning milieus in education, places with high constraints, or developing countries, to practically learn about their built heritage; consequently, contribute to its preservation. To achieve this purpose, the most diffused SFM and laser scanning open-source packages were first cross-compared using web-content analysis data collection method. Afterwards, the best programme from each category namely; Autodesk $123 D$ catch and Reconstructme, accompanied with Canon D550 camera and Xbox Kinect, respectively, were intensively evaluated through an experiment. The analysis of the findings has suggested that low-cost close-range photogrammetry can replace laser scanning when there is a lack of funding and time.
\end{abstract}

Keywords: Level of Detail (LOD), Developing Countries, Low-cost, The Built Heritage, Surveying Technologies

\section{Introduction}

$\mathrm{R}$ ecently, there has been a shift in focus towards the "built heritage" sector due to the influence of technology and global organisations such as, UNESCO, who exerted extreme pressure on heritage archiving associations. These technologies have been credited for not only overcoming conventional 2D recording systems but also accurately providing 3D models of the built heritage which range in the level of detail (LOD) according to their dedicated purpose and scale (Murphy, McGovern, and Pavia 2009, 321).

The LOD concept is not new to human beings. It an innate visual response to any object in the space. It is defined by an inverse relationship between the viewer position and any given object coordinate in the space, as illustrated in Figure 1. Technology has implemented the power of this phenomenon into several areas, the 3D modelling of the built heritage, for instance. However, despite the tremendous improvement of technologies and techniques in this field, especially in the recent years, the acquiring, processing, and visualising of architectural heritage huge data is still so costly and complex. For example, terrestrial laser scanner (TLS) costs no less than 50,000 Euro excluding post-processing software according to (Boehler and Marbs 2004, 292-294) in his comparison between laser scanning and close-range photogrammetry as depicted in table 1. In addition, other factors must be considered in order to generate accurate 3D models from masses of raw data which include; the involvement of specialised experts who must be aware of the pros \& cons of different techniques according to the required level of detail (LOD) and context (Georgopoulos et al. 2009, 22-23). Indeed, this issue was highlighted in a widely cited paper by (El-Hakim et al. 2005, 1-2) who argues that although the integration of new technologies have enabled accurate and fast modelling of monuments, it is so complex, costly, and requires hybrid approaches to visualisations of heterogonous of datasets such, survey data, CAAD drawings, photographs, and 3D non-contact imaging data (Laser scanner).

Based on the above facts, it is clear that the technologies employed at the moment in the 3D modelling of the built heritage are impractical for simplified environments despite the

The International Journal of the Constructed Environment

Volume 4, 2014, www.constructedenvironment.com, ISSN 2154-8587

(C) Common Ground, Moulay Larbi Chalal, Riccardo Balbo, All Rights Reserved

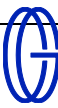


availability of new user-friendly software packages, such as VeCad, and devices for those with lower incomes. Unfortunately, they only generate low detailed 3D models which are often employed in tourism 3D visualisations (Tsioukas 2007, 2).

Apart from the immense costs and complexity of techniques, there is an unreasonable management of data in the 3D modelling of the built heritage. In other words, there is an excessive spending on 3D models with unnecessary resolution as strongly highlighted by (Remondino 2011, 1106) in the following statement “.... when a 3D model is generated, it is often subsampled or reduced to a $2 D$ drawing due to a lack of software or knowledge in properly handling $3 D$ data..." After analysing these facts, the following question will arise: How to manage the LOD (level of detail(s) in a simple, logical, and affordable way?

This study aims to examine the potential of low-cost digital acquisition technologies and modelling techniques to create multi-resolution 3D models of the built heritage in a simplified environment. This could provide potential benefits such as an economic solution, for example by using inexpensive techniques could create opportunities for potential investments into the preservation of heritage. Furthermore, reducing the level of complexity within the techniques could bring people from various backgrounds together through sharing knowledge; this will create a sense of community spirit and embed pride (Patias 2007, 235). Finally, this will help to create awareness for the preservation of our heritage and encourage future work.


olygons approx.

60.000

6.000

600

60

DISTANCE TO CAMERA

Figure 1. The principle of level of detail (LOD

Source: OpenSG 2013 
Table 1: A customised table which summarises (Boehler and Marbs 2004, 292-294) comparative research.

\begin{tabular}{|c|c|c|c|c|c|c|}
\hline \multirow{2}{*}{$\begin{array}{c}\text { Criteria } \\
\text { Technologies }\end{array}$} & \multirow{2}{*}{$\begin{array}{l}\text { Output } \\
\text { representa } \\
\text { t-ion }\end{array}$} & \multirow{2}{*}{$\begin{array}{l}\text { Cost } \\
(€)\end{array}$} & \multirow{2}{*}{ accuracy } & \multicolumn{3}{|c|}{ Type of objects studied } \\
\hline & & & & facades & Relief plate & Stone wall \\
\hline $\begin{array}{c}\text { Laser } \\
\text { scanning }\end{array}$ & $\begin{array}{l}\text { Point } \\
\text { clouds } \\
\text { model }\end{array}$ & $\begin{array}{c}50,000 \\
\text { to } \\
200,00 \\
0\end{array}$ & $\begin{array}{c}0.02 \mathrm{~mm} \\
\text { to } 4 \mathrm{~mm}\end{array}$ & $\begin{array}{c}\text { - } \\
\text { Impractical } \\
\text {-Time } \\
\text { consuming } \\
\text {-High level } \\
\text { of detail } \\
\end{array}$ & $\begin{array}{c}\text {-Realistic } \\
\text { 3D model } \\
\text {-High } \\
\text { resolution }\end{array}$ & $\begin{array}{l}\text {-Realistic } \\
\text { 3D model } \\
\text {-High } \\
\text { resolution }\end{array}$ \\
\hline $\begin{array}{l}\text { Close-range } \\
\text { photogrammet } \\
\text { ry }\end{array}$ & $\begin{array}{c}\text { 2D/3D } \\
\text { CAD } \\
\text { drawings }\end{array}$ & $\begin{array}{c}10,000 \\
- \\
30,000\end{array}$ & $\begin{array}{c}1 \mathrm{~mm} \text { to } \\
5 \mathrm{~cm}\end{array}$ & $\begin{array}{l}\text {-Adequate } \\
\text {-fast } \\
\text {-Medium } \\
\text { level of } \\
\text { detail }\end{array}$ & $\begin{array}{l}\text { Unsatisfacto } \\
\text { ry level of } \\
\text { detail } \\
\text { (LOD) } \\
\text {-Poor 3D } \\
\text { representati } \\
\text { on }\end{array}$ & $\begin{array}{c}\text { Unsatisfacto } \\
\text { ry level of } \\
\text { detail } \\
\text { (LOD) } \\
\text {-Missing } \\
\text { geometric } \\
\text { information( } \\
\text { lines- edges) }\end{array}$ \\
\hline
\end{tabular}

Source(s): Data adapted from (Boehler and Marbs 2004, 292-294) comparative research.

\section{Definition of Simplified Environments}

A simplified environment is a fast paced learning milieu which could be in education, and places with high-constraints or economic/technical resources scarcity such as developing countries. It involves low-skilled users and low-cost technologies. Furthermore, it is characterised by lowinvestments.

\section{Assessment Criteria for Simplified Environments}

Several publications have dealt with the barriers facing the prosperity of simplified environments in general and educational milieus in developing countries in particular. (Keengwe, Onchwari, and Wachira 2008, 562), categorised the factors which can affect the adoption of ICT technologies in the developing countries into three major categories namely; human factor, economical factor, and technological factor (software and hardware). However, the economical factor is not addressed in this study since only open-source packages are assessed. This will allow an idealistic situation of development.

\section{A- The Human factor}

The human factors that affect the adoption of ICT in simplified environment are mainly manifested in the lack of skills and knowledge either at students or teachers' level (Pelgrum 2001, 147). The lack of time is also considered as another critical barrier in simplified environments due to the fast paced nature of these milieus. This factor does not only affect users but also busy teachers who are obliged to bear massive workloads and admin tasks, not to 
mention depriving them of appropriate and quality training regarding hardware \& software (Duhaney 2001, 25); (Copley and Ziviani 2004, 237). Therefore, designing, planning, developing, and incorporating new technologies is beyond their capacities and control (Afshari et al. 2009, 82).

After analysing these factors, it is clear the human barriers facing the adoption of low-cost technologies and open source software in the 3D modelling of the built heritage can only be tackled by meeting the following criteria;

- Level of difficulty: Any technology either software or hardware should be assessed according to the level of its ease. The less difficult technology is the more implemented and digested by low-skilled users and vice-versa.

- Level of support: Due to the commitments of the busy educators, users should be supported by the technology itself. Therefore assessing open-source software according to their level of support is necessary.

- Amount of Time spent on training: the lack of time imposes the adoption of technologies which require hardly any training.

\section{B- The Technological factors}

The technological factors that influence the adoption of ICT in simplified milieus are usually associated with economic factors and often seen as determining factors in the growth of ICT in simplified environments. Indeed, not every technology, even cheap, can be adopted in these milieus only if certain criteria are met (Thomas 1987, 38). There have been a lot of publications which addressed the selection of appropriate technologies in educational environment in developing countries. However, (Bates 1995, 1-2) ACTIONS model is adopted in this research due to its context's clarity and the handling of innovative technologies. ACTIONS is an acronym which stands for; access, cost, teaching \& learning, interactivity and user friendliness, organisational problems, novelty, and speed. For reasons related to the ease of access to opensource packages from the web and the scope of this study, which focuses only on the implementation of low-cost technologies from users' perspective, certain criteria, such as accessibility and organisational problems, will be excluded. In conclusion, the criteria which should be considered in order to face technological barriers in this research are as follows:

- Interactivity and user friendliness

- Level of support in teaching \& learning

\section{Research Methodology}

This research embraces a combination of both qualitative and quantitative research methodologies due to some reasons. First, the large number of existing open-source software packages on the 3D modelling of the built heritage, has required the adoption of a rigorous selective process based on a manageable sample and according to criteria related to users' experiences, such as level of support and users' satisfaction. For these reasons, qualitative research methodology was implemented. On the other hands, the high precision, flexibility, and control required in determining or comparing the level of detail (LOD) in the surveyed 3D models have imposed the adoption of quantitative research methodology (Morgan 1998, 9).

In order to allow a deep assessment of both low-cost software and hardware, a multitriangulation design which consists of three levels of implementations with an overall interpretation namely; sampling, sample analysis, and LOD comparison, has been applied as shown in figure 2. The power of this implementation design lies in its solid theoretical foundation, great flexibility, and comprehensive answers to the research problems (Connelly 2009, 31-32). Sampling, which is the first implementation level in this research, consists of selecting carefully a small family of 5 software packages among dozens on the web. This was 
achieved by using web-content analysis as a quantitative data collection method to analyse 20 multiple web resources according to certain criteria namely; cost, software ranking on the web, the level of Popularity, level of support, and users' satisfaction. Once the five packages were determined and ranked, the next phase of implementation, which is sampling analysis, occurred. This stage comprised focus groups with low-skilled users as well as web-content analysis as qualitative data collection tools in order to investigate the reliability of the results of the previous phase (sampling). This inspection followed some criteria namely; user interface according to (Bastien and Scapin 1995, 106-110) model, level of training and difficulty, interoperability, and independency. Finally, the last level of implementation which consists of an experiment, explained in detailed in the following paragraph, took place after the five packages had been reranked in the second phase (sample analysis).



Figure 2: The multi triangulation design adopted in this research.

\section{Experimental Research}

The experiment aims to extensively compare the level of detail(s) LOD in the 3D models generated by two low-cost devices namely; Xbox Kinect and Canon D550, accompanied by the best two applications from the sample analysis phase. In order to ensure the success of this experiment, which represents the backbone of this research, it was tightly controlled by isolating environmental and technical factors that may affect the capacity of these devices. Environmental factors are manifested in the sensitivity of the XBOX sensor to sunlight. To overcome this obstacle, the experiment was held in an artificial environment (indoor) in which light was well controlled. On the other hand, technical issues occurs when certain requirements, such as devices' calibration and acquisition' range, are not met. This was prevented by accurately calibrating the devices, understanding their processing pipelines, and ranges limitation.

The implementation of the experiment, which is explained in detail in Figure 3, consisted of four major steps namely; mock-up's production, generation of referential model, generation the compared 3D models, and comparing the level of detail (LOD). First, since the experiment was held indoor, a 3D model of the complex and rich neoclassic façade of the New York stock exchange was printed in 1:50 scale with Roland CNC milling machine as illustrated in figure 4. Once accomplished, the printed physical model was acquired as a referential 3D model using Z800 handheld scanner with an accuracy of $1 \mathrm{~mm}$ as represented in Figure 5. Afterwards, Xbox Kinect and Canon D550 devices followed by reconstruct ME as well as Autodesk 123D catch software, respectively, were used to survey the physical model (Figure 6, 7). Finally, the two 
generated 3D models were compared based on visual observations and the evaluation of Gaussian deviation after being aligned to the referential model.

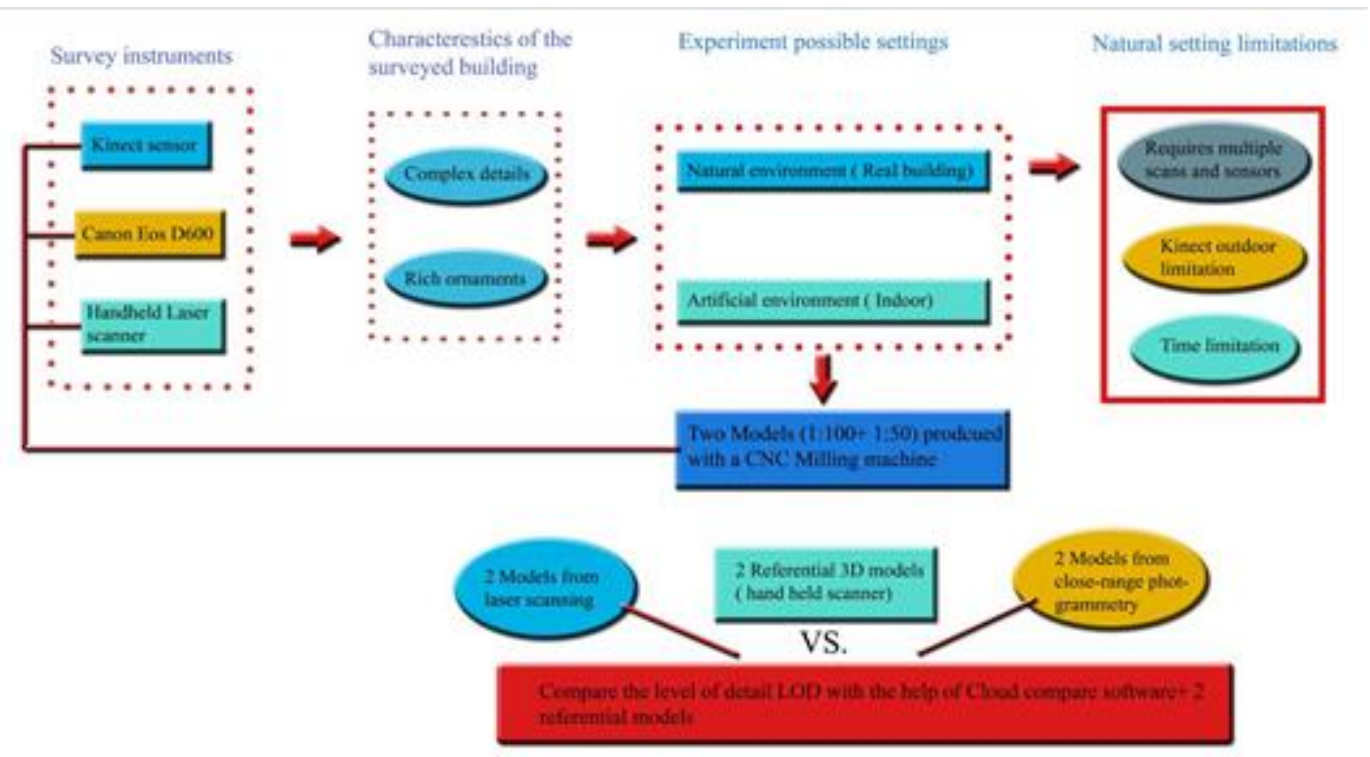

Figure 3: A diagram which illustrates in detail the implementation of the experiment in the undertaken research.


Figure 4: The New York stock exchange on the right, and its 3D model being printed with CNC milling machine on the left.

Source: WTComplete et al. 2009 

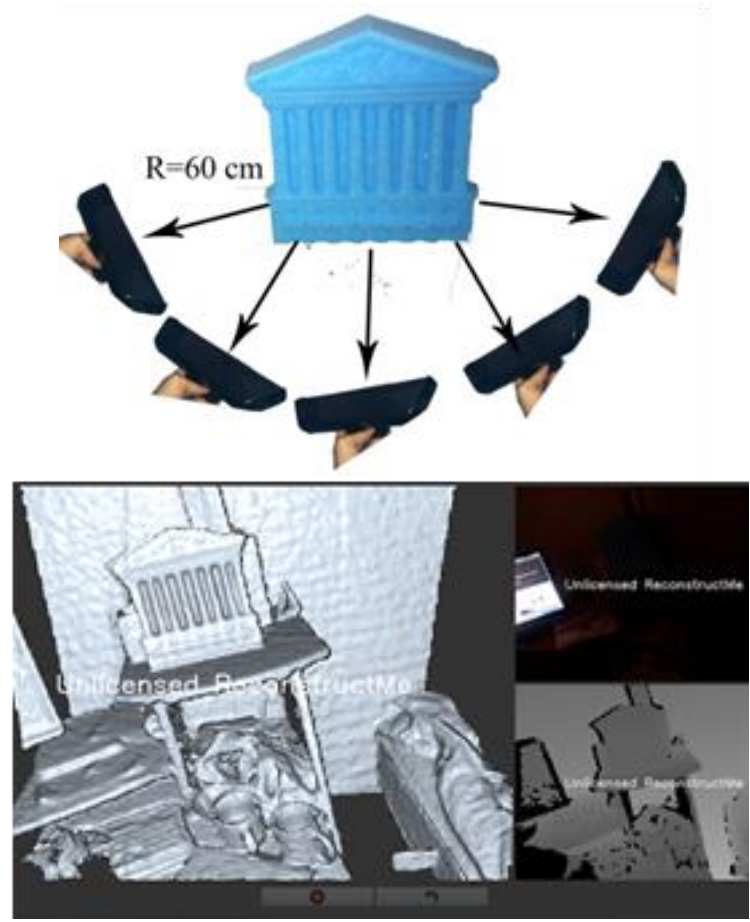

Figure 5: An illustration of the acquisition process with Reconstructme and Xbox Kinect in the experiment

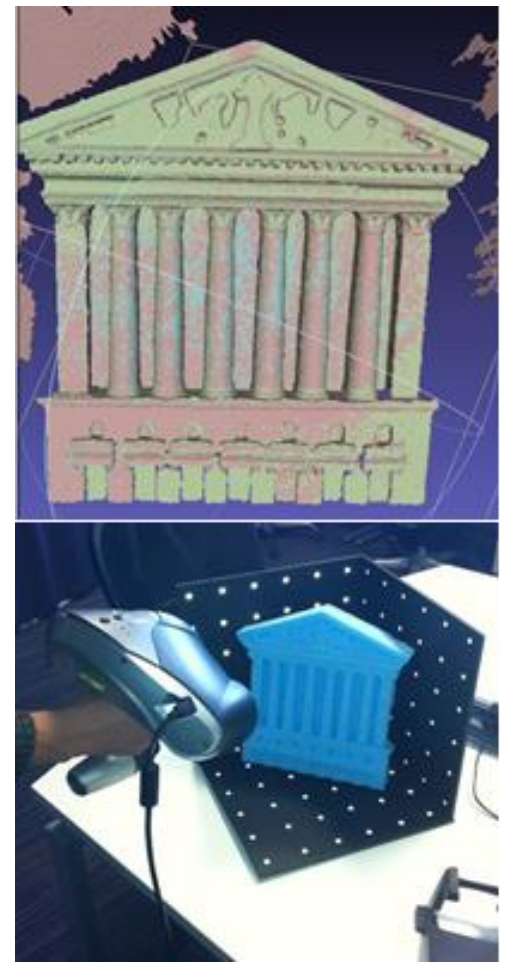

Figure 6: The referential 3D model is being recorded by z800 scanner. 


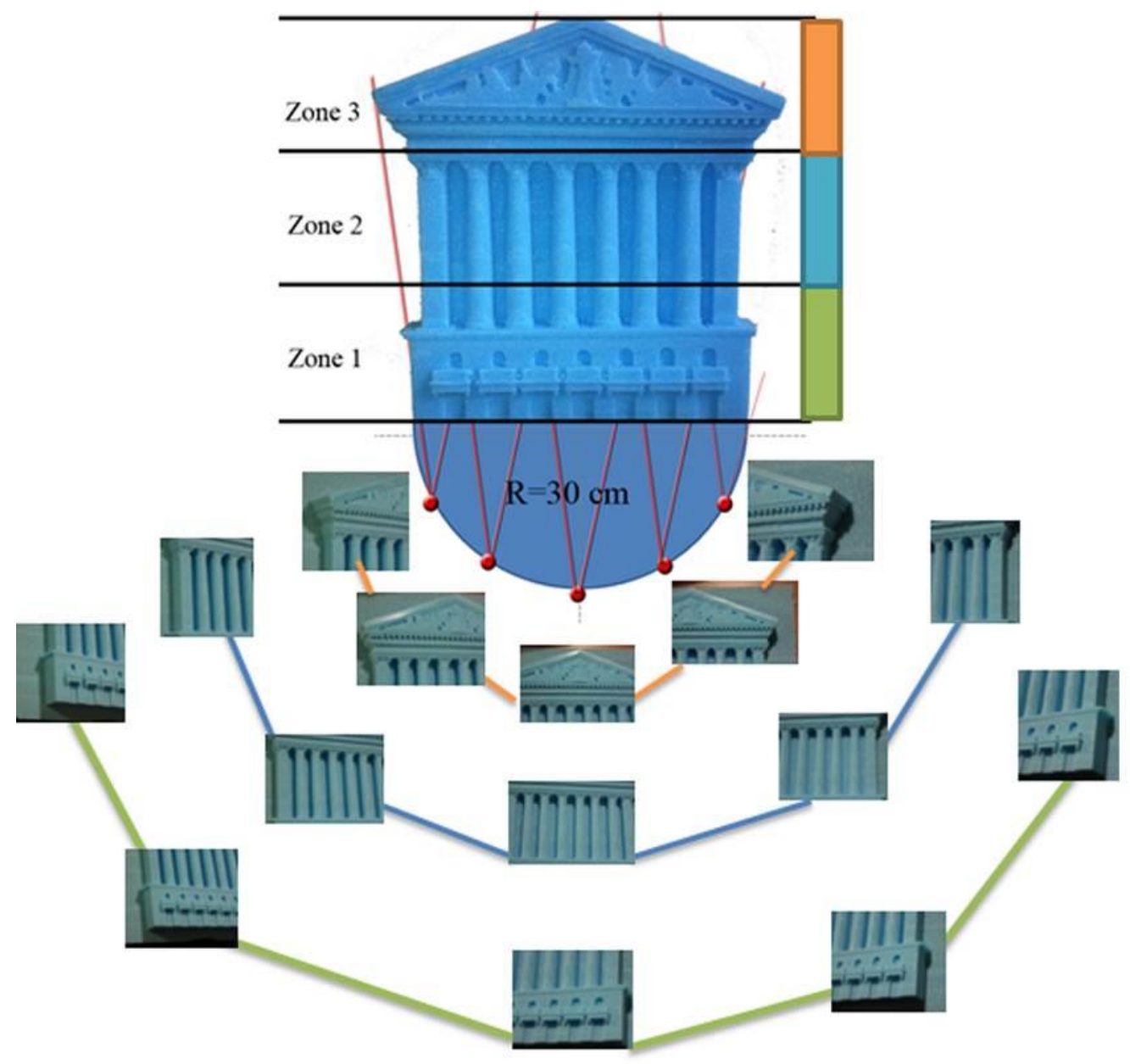

Figure 7: An illustration of the acquisition process with 123D catch and Canon D550 in the experiment

\section{Results and Discussion}

\section{A-Visual Observations}

Figure 8 compares the overall produced 3D models, whereas, Figure 9 is a zoomed in comparison of certain parts in both 3D models. The 3D model created with 123D catch was not only denser than the Reconstructme one but also so realistic in terms of textures and well level of detail even at a very high resolution, apart from minor imperfections. On the other hand, very important details, such as the tympanum, the frieze, the columns' capitals, and the balconies were not present at all in the Reconstructme 3D model. 

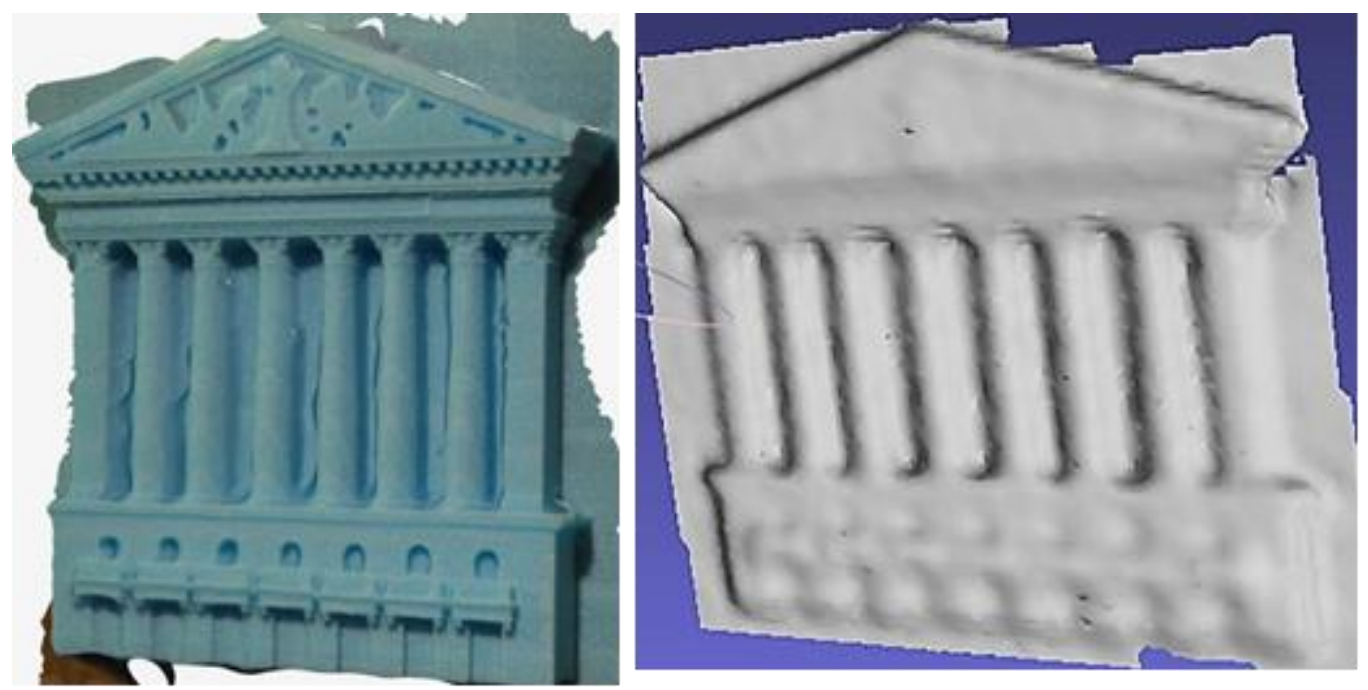

Figure 8: 123D catch model (on the left) and the Reconstructme one on the right
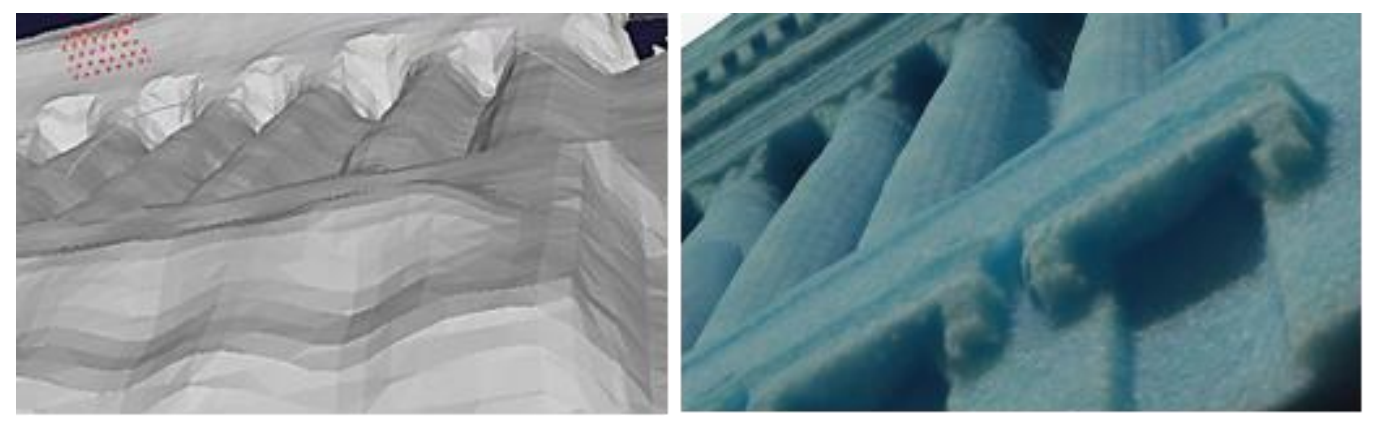

Figure 9: A zoomed Comparison of the balconies part in 123D catch and Reconstructme 3D models on the left

\section{B- Gaussian Distribution Analysis}

The figures $(9,10)$ represent the distribution of deviations (Gaussian distribution) between the assessed and the referential 3D model through a colour scale. First, the comparison of 123D catch with the referential model has shown that 123D catch model was not only so homogeneous but also accurate as most of the areas were displayed in green and the average distance was $1.4 \mathrm{~mm}$. This distance would have been $1 \mathrm{~mm}$ if the areas between the columns were retouched with external packages such as Maya. On the other hand, the 3D model obtained with Reconstructme was inaccurate and less homogenous as the majority of areas on the models were brown as well as the average distance was $3.5 \mathrm{~mm}$. This distance was greater $(4 \mathrm{~mm})$ in critical areas such as the entablature and columns area where there is a considerable level of detail (LOD). 



Figure 9: The deviation analysis of Reconstructme 3D model
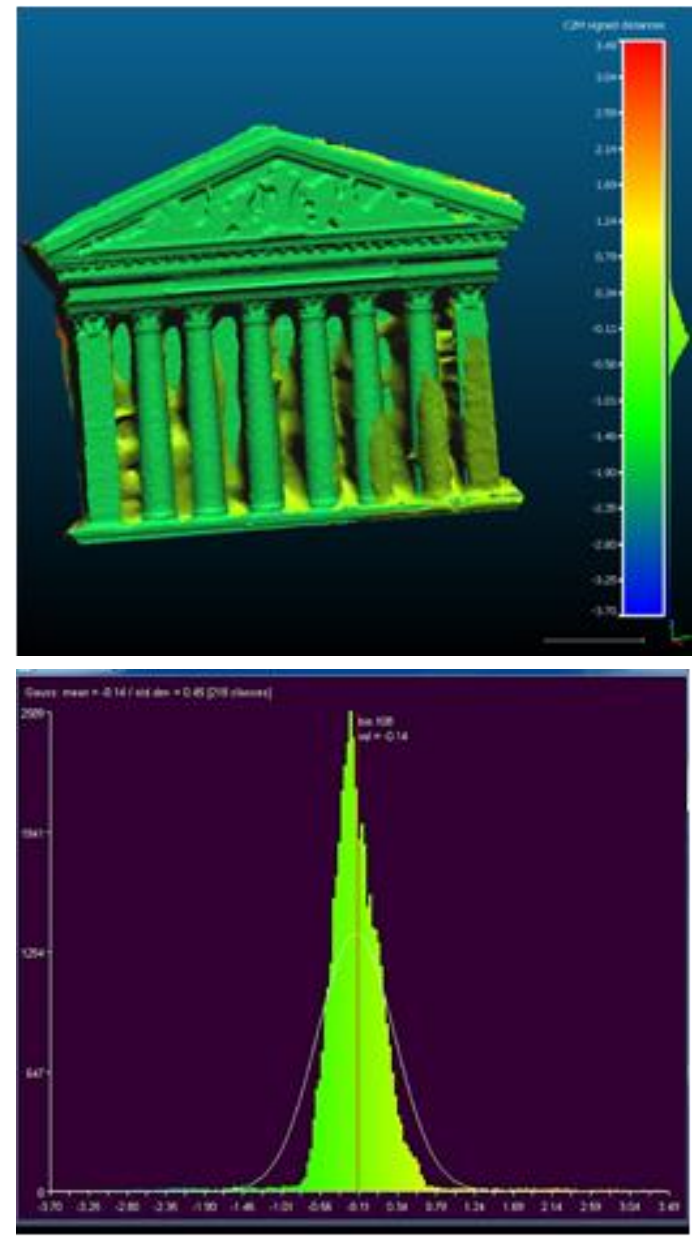

Figure 10: The deviation analysis of $123 \mathrm{D}$ catch 3D model

After analysing the experiment results, it is clear that low-cost close range photogrammetry, which is supported by amateur cameras, Canon D550 for instance, is more convenient than lowcost laser scanning aided by Kinect sensor at the time being in many aspects as shown in table 2 . The former device has provided impressive 3D models in terms of texture, accuracy, and level of detail (LOD) as it was hard to distinguish between the actual 3D model and the virtual one. Furthermore, it has offered a considerable assistance and flexibility in the acquisition of images. On the other hand, Xbox Kinect has not only generated poor quality 3D data but also created challenges during the acquisition process due to the following reasons;

- Kinect's RGB camera low-resolution: Although this device employs a high resolution infrared sensor $(1,280 \times 1,024)$ pixels, its internal processor reduce this resolution to the one of RGB camera $(640 \times 480)$ pixels (Chipworks 2013).Therefore, the 3D models obtained by Canon D550 was far much better in terms of LOD as its resolution is 60 times higher than the one of the Kinect $(0.3$ mega pixels). 
- The low-depth of Kinect: this is due to the Kinect's limited range which does not go beyond $500 \mathrm{~mm}$. Furthermore, its low colour depth (11bits) which is the half depth of canon D550 (22.1 bits). This makes this device redundant when acquiring small details.

Table 2: Summary of the main findings

\begin{tabular}{|c|c|c|c|c|c|c|}
\hline & Category & $\begin{array}{l}\text { The condition } \\
\text { of the } \\
\text { generated 3D } \\
\text { models }\end{array}$ & $\begin{array}{l}\text { Level of } \\
\text { detail } \\
\text { (LOD) }\end{array}$ & $\begin{array}{c}\text { Standard } \\
\text { Deviation }\end{array}$ & $\begin{array}{c}\text { Hardware } \\
\text { Limitatio } \\
\text { ns }\end{array}$ & $\begin{array}{l}\text { Software } \\
\text { Limitations }\end{array}$ \\
\hline $\begin{array}{l}\text { Autodesk } \\
123 \mathrm{D} \\
\text { catch } \\
+ \text { Canon } \\
\text { D550 }\end{array}$ & $\begin{array}{l}\text { Low-cost } \\
\text { close range } \\
\text { photogram } \\
\text { metry + } \\
\text { SFM }\end{array}$ & $\begin{array}{l}\text {-Smooth } \\
\text {-Realistic } \\
\text { textures } \\
\text {-minor holes } \\
\text { behind the } \\
\text { entablature and } \\
\text { between } \\
\text { columns }\end{array}$ & $\begin{array}{l}\text { Highly } \\
\text { detailed } \\
\text { 3D } \\
\text { models } \\
\text { with a } \\
\text { great } \\
\text { resolution }\end{array}$ & $1.4 \mathrm{~mm}$ & $\begin{array}{c}\text { minor } \\
\text { lens } \\
\text { distortion }\end{array}$ & $\begin{array}{l}\text {-Privacy } \\
\text { issue } \\
\text {-lack of } \\
\text { customization } \\
\text { of the } \\
\text { reconstructio } \\
\text { n process } \\
\text {-non- } \\
\text { supportive } \\
\text { post- } \\
\text { processing } \\
\text { environment }\end{array}$ \\
\hline $\begin{array}{c}\text { Reconstru } \\
\text { ctme }+ \\
\text { Xbox } \\
\text { Kinect }\end{array}$ & $\begin{array}{l}\text { Low-cost } \\
\text { laser } \\
\text { scanning }\end{array}$ & $\begin{array}{c}\text {-Rough } \\
\text { - Lack of any } \\
\text { colour } \\
\text { information }\end{array}$ & $\begin{array}{c}\text { - Lack of } \\
\text { geometric } \\
\text { informati } \\
\text { on } \\
\text { - poor } \\
\text { level of } \\
\text { detail( } \\
\text { LOD) }\end{array}$ & $3.5 \mathrm{~mm}$ & $\begin{array}{c}\text {-Low } \\
\text { depth and } \\
\text { resolution } \\
- \\
\text { sensibilit } \\
\text { y to light } \\
\text { sources. } \\
\text { - low- } \\
\text { range } \\
\text { (500- } \\
5000 \mathrm{~mm} \\
- \\
\text { Non } \\
\text { portable }\end{array}$ & $\begin{array}{l}\text {-Lack of } \\
\text { post- } \\
\text { processing } \\
\text { features } \\
\text {-lack of self- } \\
\text { 3D } \\
\text { orientation } \\
\text {-Lack of } \\
\text { editing } \\
\text { features }\end{array}$ \\
\hline
\end{tabular}

\section{Conclusions and Recommendations for Future Work}

The hypothesis stated in the introduction regarding whether or not low-cost technologies are able to provide medium or high level of detail (LOD) is difficult to be answered by taking account of both categories, close-range photogrammetry and laser scanning. However, by only considering low-cost close range photogrammetry, which is well supported by Autodesk 123D catch and some affordable cameras, the answer can be "YES". This technology is an adequate alternative to 
terrestrial laser scanning when there is a lack of time and funding. Therefore, its adoption in simplified environments is so convenient in terms of time efficiency, ease, and cost. It is believed that, conducting further research on developing SFM packages such as 123D catch will optimise the management of LOD in the 3D modelling of the built heritage.

In contrast to the above category, Microsoft Kinect which is successfully implemented in different disciplines such as surgery, can unfortunately not be employed in the 3D modelling of the built heritage in simplified environment at the moment due to its unacceptable level of detail LOD, low range and accuracy.

This research has undoubtedly highlighted so many directions for future development in the built heritage sector in general and simplified environments in particular. Among them it is very interesting to mention that despite the fact that XBOX Kinect is technically limited in surveying historical buildings at the time being due to its low-colour depth as well as resolution, it could be easily improved through a simple collaboration between building surveyors, IT engineers, and electronics engineers. Therefore, we would strongly recommended the enhancement of the capacities of following parts namely; RGB camera, IR camera, and Processor, in order to enable the integration of this device in the $3 \mathrm{D}$ modelling of the built heritage in simplified environments.

\section{Acknowledgment}

We would like to take this opportunity to acknowledge Dr. Tuba Kocaturk, Prof. Medjedoub Benachir, Prof. Arto Kiviniemi, Dr. May Bassanino, Mr. Alejandro Veliz, Mr. Vincenzo Donato and Mr. Chet Narsih for their invaluable contribution to this research. 


\section{REFERENCES}

Afshari, Mojgan, Kamariah Abu Bakar, Wong Su Luan, Bahaman Abu Samah, and Foo Say Fooi. 2009. "FACTORS AFFECTING TEACHERS' USE OF INFORMATION AND COMMUNICATION TECHNOLOGY." International Journal of Instruction no. 2 (1):77-104.

Bastien, JM Christian, and Dominique L Scapin. 1995. "Evaluating a user interface with ergonomic criteria." International Journal of Human-Computer Interaction no. 7 (2):105-121.

Bates, T. 1995. Technology, Open Learning, and Distance Education. London: Routledge.

Boehler, W., and A. Marbs. 2004. "3D Scanning And Photogrammetry For Heritage Recording A Comparison." Paper presented at Geoinformatics, Proc. 12th Int. Conf. on Geoinformatics - Geospatial Information Research: Bridging the Pacific and Atlantic, at Gävle, Sweden.

Chipworks. 2013. "Teardown of the Microsoft Kinect-Focused on motion capture 2013." Accessed July 15 2013. Available from http://www.chipworks.com/en/technicalcompetitive-analysis/resources/recent.

Connelly, L. M. 2009. "Mixed methods studies." Medsurg Nurs no. 18 (1):31-2.

Copley, Jodie, and Jenny Ziviani. 2004. "Barriers to the use of assistive technology for children with multiple disabilities." Occupational Therapy International no. 11 (4):229-243. doi: 10.1002/oti.213.

Duhaney, D. C. 2001. "Teacher education: Preparing teachers to integrate technology." International Journal of Instructional Media no. 28 (1):23-30.

El-Hakim, Sabry, Jean-Angelo Beraldin, L Gonzo, E Whiting, M Jemtrud, and V Valzano. 2005. "A hierarchical 3D reconstruction approach for documenting complex heritage sites." Paper presented at The XX CIPA International Symposium, at Torino, Italy

Georgopoulos, A., Ioannidis Ch, Chrysostomou Ch, S. Ioakim, N. Shieittanis, and M. Ioannides. 2009. "Contemporary Digital Methods for the Geometric Documentation of Churches in Cyprus." International Journal of Architectural Computing no. 7 (1):21-37. doi: $10.1260 / 147807709788549358$.

Keengwe, Jared, Grace Onchwari, and Patrick Wachira. 2008. "Computer Technology Integration and Student Learning: Barriers and Promise." Journal of Science Education and Technology no. 17 (6):560-565. doi: 10.1007/s10956-008-9123-5.

Morgan, D.L. 1998. The focus group guidebook: SAGE Publications.

Murphy, Maurice, Eugene McGovern, and Sara Pavia. 2009. "Historic Building Information Modelling - Adding intelligence to laser and image based surveys of European classical architecture." ISPRS Journal of Photogrammetry and Remote Sensing:311-327. doi: 10.1016/j.isprsjprs.2012.11.006.

OpenSG. 2013. "NodeCores." Accessed May 24 2013. Available from http://www.opensg.org/projects/opensg/wiki/Tutorial/OpenSG2/NodeCores.

Patias, Petros. 2007. "Cultural heritage documentation." In Applications of $3 D$ measurement from images, edited by J. Fryer, H. Mitchell and J.H. Chandler, 225-250. Dunbeath, UK: Whittles.

Pelgrum, W. J. 2001. "Obstacles to the integration of ICT in education: results from a worldwide educational assessment." Computers \& Education no. 37 (2):163-178. doi: 10.1016/s0360-1315(01)00045-8.

Remondino, Fabio. 2011. "Heritage Recording and 3D Modeling with Photogrammetry and 3D Scanning." Remote Sensing no. 3 (6):1104-1138. doi: 10.3390/rs3061104.

Thomas, R. M. 1987. "Computer technology: an example of decision-making in technology transfer." In Educational Technology-Its Creation, Development and Cross-Cultural 
Transfer, edited by R. M. Thomas and V. N. Kobayashi, 25-34. Oxford: Pergamon Press.

Tsioukas, V. 2007. "SIMPLE TOOLS FOR ARCHITECTURAL PHOTOGRAMMETRY." Paper presented at at 21st CIPA symposium AntiCIPAting the future of the cultural past, at Athens, Greece.

WTComplete, Brandon, Karlfucious, and KDDesign. 2013. "New York Stock Exchange Building(11 Wall Street, New York)."Accessed August 23 2013.Available from http://sketchup.google.com/3dwarehouse/details?mid=70edcbe1d1d732dc7752bd0cec0c $2 \mathrm{a} 35$.

\section{ABOUT THE AUTHORS}

Moulay Larbi Chalal: Student, The School of the Built Environment, The University of Salford Manchester, Salford, Greater Manchester, UK.

Riccardo Balbo: Lecturer, Politecnico di Torino, Turin, Italy. 